\title{
Preparation and Characterization of Carbon Nanofluids by Using a Revised Water-Assisted Synthesis Method
}

\author{
Tun-Ping Teng, Li Lin, and Chao-Chieh Yu \\ Department of Industrial Education, National Taiwan Normal University, No. 162, Section 1, He-ping E. Road, \\ Da-an District, Taipei City 10610, Taiwan
}

Correspondence should be addressed to Tun-Ping Teng; tube5711@ntnu.edu.tw

Received 24 August 2013; Accepted 25 September 2013

Academic Editor: Zhenhui Kang

Copyright (C) 2013 Tun-Ping Teng et al. This is an open access article distributed under the Creative Commons Attribution License, which permits unrestricted use, distribution, and reproduction in any medium, provided the original work is properly cited.

\begin{abstract}
A revised water-assisted synthesis system (RWAS) was used to fabricate carbon/water nanofluids (CWNFs). The CWNFs were manufactured by heating graphite rods at different temperatures $\left(700,800,900\right.$, and $\left.1000^{\circ} \mathrm{C}\right)$. Aspects of the CWNFs and suspended nanocarbon, such as the morphology, structure, optical characteristics, and production rate, were fully characterized. Furthermore, the suspension performance of the CWNFs was controlled by adding a dispersant (water-soluble chitosan) at different concentrations. Finally, the CWNFs were determined to assess the influence of both the heating temperature of the graphite rod module (process temperature) and the dispersant concentration on the fundamental characteristics of the CWNFs. The results showed that the nanocarbon was a mixture of nanocrystalline graphite and amorphous carbon. Heating the graphite rod module at higher process temperatures resulted in a higher production rate and a greater nanocarbon particle size. Furthermore, adding dispersant could improve the suspension performance; increase the viscosity, density, and specific heat; and reduce the thermal conductivity of the CWNFs. The optimal combination of the process temperature range and dispersant concentration was 800 to $900^{\circ} \mathrm{C}$ and $0.2 \mathrm{wt} . \%$, respectively, based on the production rate, suspension performance, and other fundamental properties of the CWNFs.
\end{abstract}

\section{Introduction}

Nanoscale materials are added to working fluids to form stable suspensions called "nanofluids" [1]. Nanofluids can be used in several applications to boost the efficiency of systems or processes by improving thermal properties and heat transfer performance. Numerous in-depth studies of nanofluids have addressed manufacturing methods, fundamental characteristics, heat transfer performance, transportation behavior, and the practical application of existing equipment to improve efficiency. Studies on the fundamental characteristics of nanofluids have focused mainly on their thermal conductivity, density, viscosity, specific heat, and suspension performance [2-10]. Studies on the heat transfer performance of nanofluids have focused mainly on their heat transfer performance, pressure drop, and pumping power in a single tube [11-15] or heat exchanger [16-21] with different geometries. Current uses of nanofluids include vehicle cooling systems, heat recovery systems, refrigeration and air conditioning systems, and solar collectors [22-27].
Because of their excellent fundamental characteristics, nanofluids are used to improve the system performance and efficiency of equipment. Nevertheless, the long-term suspension performance of nanofluids and their price are key factors to consider. The suspension performance and price of nanofluids depend on the manufacturing methods. Generally, the synthesis of nanofluids can be divided into one-step synthesis methods and two-step synthesis methods.

One-step synthesis methods involve directly fabricating nanoparticles in the base liquid to form the nanofluid. Onestep synthesis is generally performed using the sputtering method [28-30], arc discharge method [6, 31-33], laser ablation method [34-36], water-assisted synthesis method $[37,38]$, and chemical reaction-generated method [39-42]. Generally, one-step synthesis has self-screening mechanisms for particle size, in which excessively large particles automatically settle on the bottom of the container, whereas ultra-fine particles are suspended in the liquid. Nanofluids with excellent suspension performance can be obtained by removing the precipitated particles or using a centrifuge to control the 
size of the suspended particles. Therefore, a small amount of dispersant or surfactant is needed to improve the suspension performance of nanofluids produced by one-step synthesis methods. However, the disadvantage of one-step synthesis methods is that preparation and process conditions influence the size, shape, and concentration of the nanoparticles, resulting in a broad range of particle sizes and difficulties in controlling the concentration.

In two-step synthesis methods, the nanoparticles are first produced and then dispersed in a base liquid to form the nanofluid. Dispersion processes for two-step synthesis mainly include mechanical agitation (magnetic stirrer, homogenizer, and mixer) [5, 8-11, 20, 27], ultrasonic dispersion (ultrasonic bath, ultrasonic processor, and ultrasonic disruptor) $[2-5,7-21,27,43,44]$, and grinding [45]. Furthermore, adding a stabilizer (dispersant or surfactant) [2, 4, 8-10, $16,18,20,25,27,43-45]$ or adjusting the $\mathrm{pH}$ value $[4,14$, $17-19,24,25]$ of nanofluids can improve their suspension performance and enhance their practicality and long-term stability. Generally, two-step synthesis methods are simpler than one-step synthesis methods because the nanoparticles may be either self-made or purchased and then added to a base liquid to form nanofluids. The advantages of twostep synthesis methods compared with one-step synthesis methods are easy and rapid preparation of a large volume of nanofluids, greater control over nanoparticle concentration, and narrower particle size distribution. However, agglomeration can occur easily during nanoparticle addition, resulting in poor suspension. Thus, two-step synthesis often requires dispersion equipments or the addition of a stabilizer (surfactant or dispersant) to disrupt the agglomeration of nanoparticles, provide dispersion, and stabilize the suspension in the long term.

In this study, we used a revised water-assisted synthesis system (RWAS) to fabricate carbon/water nanofluids (CWNFs) in a one-step synthesis process. The CWNFs were manufactured by heating graphite rods at different temperatures. To demonstrate the feasibility of the process, the CWNFs were fully characterized using suitable instruments and test methods. The morphology, structure, particle size, suspension performance, production rate, and other fundamental properties were determined.

\section{Preparation of Carbon Nanofluids}

We applied the water-assisted synthesis method (WAS) [37, 38], which is a single-step synthesis method, to prepare the CWNFs. In this method, graphite rods are heated at a high temperature, and then rapidly cooled in cold water, producing a slight explosion on the surface of the graphite rods, which peel off the surface of the graphite rods to generate nanocarbon (carbon nanoparticles or carbon nanotubes $(\mathrm{CNTs}))$ in water because rapid expansion and contraction result from the temperature difference. The production rate and morphology of the nanocarbon mainly depend on the temperature difference between heating and cooling. A stable temperature difference can improve the repeatability of the various process parameters. Therefore, we adopted a cooling system for the WAS to generate an RWAS for CWNFs

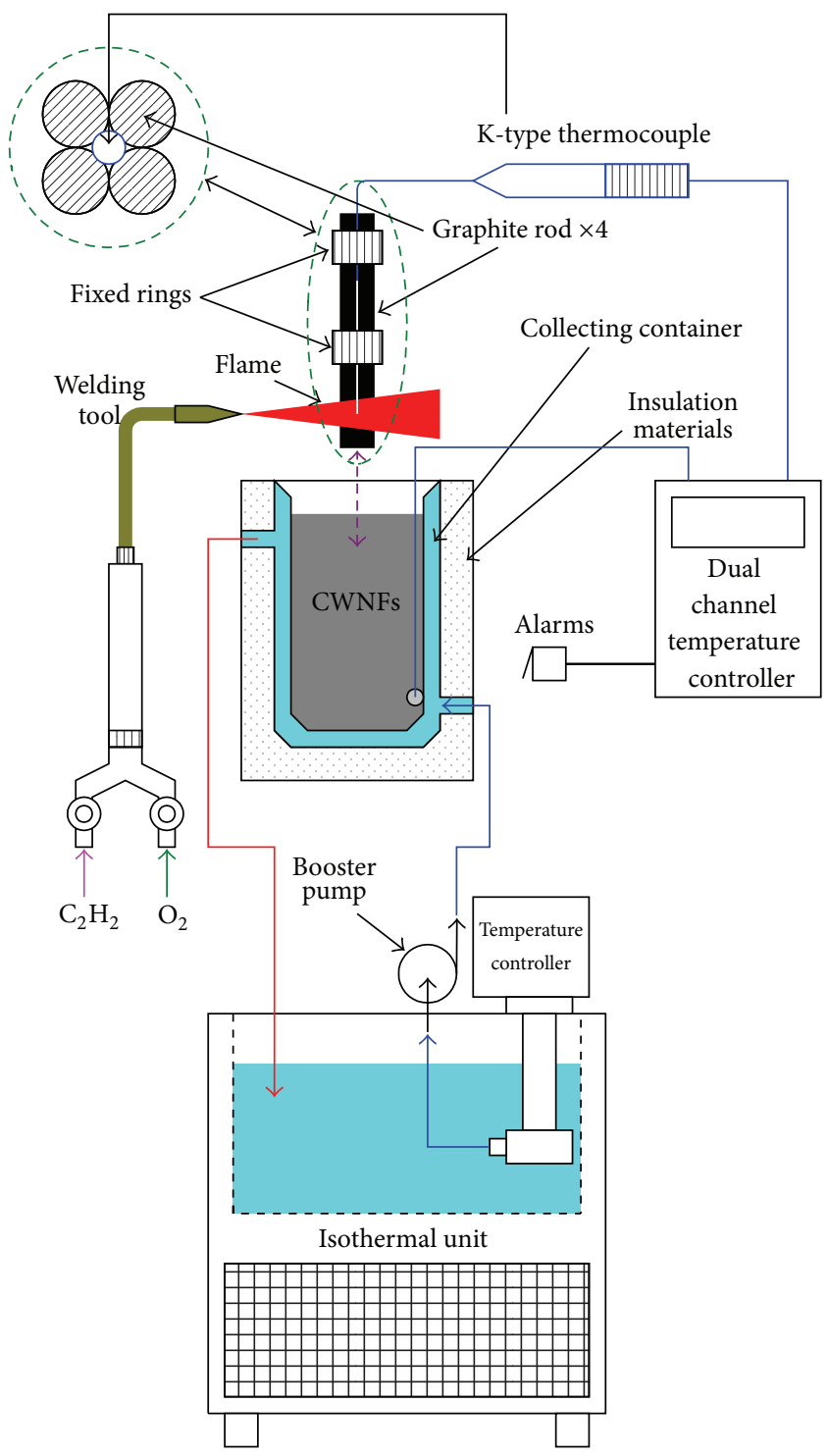

FIGURE 1: Schematic layout of the RWAS system.

fabrication. Figure 1 shows a schematic layout of the RWAS. RWAS has a cooling system that suppresses the increasing temperature of the CWNFs during the manufacturing process to improve their quality and the reproducibility of the process.

Oxygen $\left(\mathrm{O}_{2}\right)$-acetylene $\left(\mathrm{C}_{2} \mathrm{H}_{2}\right)$ welding equipment was the heat source, and a graphite rod module, temperature controller, collecting container, and cooling system were integrated to complete the RWAS system. The $\mathrm{O}_{2}-\mathrm{C}_{2} \mathrm{H}_{2}$ welding equipment was used to heat the graphite rod module at 700 , 800,900 , and $1000^{\circ} \mathrm{C}$ (process temperature), and the $\mathrm{O}_{2}$ and $\mathrm{C}_{2} \mathrm{H}_{2}$ gas pressures were $2.5 \mathrm{~kg} / \mathrm{m}^{2}$ and $0.3 \mathrm{~kg} / \mathrm{m}^{2}$, respectively. The graphite rod module consisted of four graphite rods $(\phi=8 \mathrm{~mm}, L=150 \mathrm{~mm})$ attached to a hightemperature thermocouple (K-type, $1200^{\circ} \mathrm{C}$ ) by two stainless steel retaining rings. Graphite rods for general chemistry experiments were used for the electrode, and the purity of the graphite rods (carbon content $>90 \%$ ) was confirmed using 
energy dispersive spectroscopy (EDS). The high-temperature thermocouple, which was covered with a stainless steel tube, was located in the internal center of the rod module and closely contacted the rods. Because the graphite rod and stainless steel tube had good thermal conductivity, the thermocouple could effectively detect the average temperature of the four graphite rods. The temperature controller was used to monitor the temperature of both the graphite rod module and sample in the collecting container. The collecting container was made of a double-walled stainless steel cup, and the coolant (ethylene glycol: water, 20:80 v/v) flowed through the inner space between the double wall to stabilize the temperature of the sample in the collecting container.

To manufacture the CWNFs, $300 \mathrm{~mL}$ of filtered water was poured into the collecting container. The isothermal unit ( $\mathrm{P}-$ 10 , YSC, Taiwan) was turned on for the coolant to reach $-5^{\circ} \mathrm{C}$, and then the coolant was pumped to keep the water in the collecting container in a range of 3 to $5^{\circ} \mathrm{C}$. Subsequently, the graphite rod module was heated to the set temperature by an $\mathrm{O}_{2}-\mathrm{C}_{2} \mathrm{H}_{2}$ flame, and then the red-hot graphite rod module was quickly and vertically put into the water of the collecting container for cooling. The graphite rod module was taken out after cooling for 10 seconds to finish the fabrication process of the CWNFs. The temperature of the CWNFs in the container was increased from 35 to $45^{\circ} \mathrm{C}$ during the cooling process of the graphite rod module. Based on the heating temperature of the graphite rod module, the cooling system effectively suppressed the temperature increase of the CWNFs. Finally, to improve the suspension performance of the nanocarbon in the base liquid, the collected CWNFs were stirred using a stirrer/hot plate (PC420D, Corning, USA) operating at $600 \mathrm{rpm}$ for 1 hour, homogenized at $6000 \mathrm{rpm}$ for 30 minutes by homogenizer (YOM300D, Yotec, Taiwan), and subjected to an intermittent oscillation process (50\% amplitude, on/off duty was 10/10 seconds) using an ultrasonic liquid processor (Q700, Qsonica, USA) for 30 minutes. Using these dispersal devices 5 times effectively prevented a temperature increase in the dispersion equipment and the CWNFs, achieving a good dispersion effect for the CWNFs. After completing the production of the dispersed CWNFs, we conducted a series of examinations to determine the characteristics of the materials.

\section{Characteristics Analysis}

Before testing or sampling, each sample was dispersed using an ultrasonic bath (150 W, Leo-150S, Leo, Taiwan) for 30 minutes and then statically placed for 10 minutes. This procedure was conducted to maintain the approximate initial measurement conditions.

3.1. Analysis of Morphology and Structure. The nanocarbon morphologies of the CWNFs were analyzed by using a highresolution field-emission scanning electron microscope (HRFESEM, S4800, Hitachi, Japan) and a transmission electron microscope (TEM, H-7100, Hitachi, Japan). Aso, the shape and size of the nanocarbon were determined. To understand the structure and crystallization of the nanocarbon, Raman spectroscopy (632.8 nm, TRIAX 550, HORIBA, Japan) and
X-ray diffraction (XRD, D8 Advanced, Bruker, Germany) were used to detect the Raman shift of its D peak, G peak, and crystallization of the nanocarbon, respectively.

3.2. Analysis of Optical Characteristics. A UV/VIS/NIR spectrometer (V670, Jasco, Japan) was used to measure the transmittance and absorbance of each sample at wavelengths from 400 to $1000 \mathrm{~nm}$ to identify the optical characteristics of the CWNFs. These optical characteristics are helpful in determining the possible applications of the CWNFs.

3.3. Production Rate of Nanocarbon. The production rate of nanocarbon for each process parameter was measured to determine the concentration of nanocarbon in the CWNFs. For each process parameter, CWNFs $(30 \mathrm{~g})$ were heated using a moisture analyzer (MX-50, A\&D, Japan) to remove the moisture, and then the nanocarbon concentration in the CWNFs was estimated based on the remaining weight (weighing method). Because the highest resolution of the moisture analyzer was $1.0 \mathrm{mg}$, to improve accuracy, we used a high-precision electronic balance $(0.1 \mathrm{mg} / 125 \mathrm{~g}, \mathrm{XS125A}$, Precisa, Switzerland) to weigh samples before and after drying. The entire experimental procedure was repeated 5 times, and the data were averaged as the weight concentration of the CWNFs. In addition, the absorbance change of the CWNFs was measured by using a UV/VIS/NIR spectrometer (V670, Jasco) to be compared with the results of quantitative weighing method for CWNFs by the RWAS system.

3.4. Particle Size and Suspension Performance Analysis. Different concentrations of water-soluble chitosan (C06, Charming \& Beauty, Taiwan) $[5,10,20,46]$ were added to the CWNFs as dispersants to investigate how the amount of added dispersant affected their suspension performance and agglomeration behavior. The dispersant concentrations were $0.1,0.2,0.3$, and 0.4 wt.\%. For effective dispersion, the CWNFs and dispersant were mixed by using an ultrasonic liquid processor (Q700, Qsonica, USA) for 5 minutes (50\% amplitude).

To determine the effects of both different concentrations of nanocarbon and dispersant on the suspension performance, the CWNFs were tested by using a static position method, a UV/VIS/NIR spectrometer (V670, Jasco), and a particle size/zeta potential analyzer (SZ-100, HORIBA, Japan). For the static position method, a $2.5-\mathrm{mL}$ sample was put into a transparent cuvette, and the sediment difference was observed after 12 hours. UV/VIS/NIR spectrometry combined with static positioning was performed to measure the difference in the absorbance of the initial $\left(\mathrm{Abs}_{i}\right)$ and static position of the CWNFs after 12 hours $\left(\mathrm{Abs}_{12 \mathrm{hr}}\right)$. The results were used to determine the suspension performance, which was calculated using (1). Greater absorbance difference ratio $\left(R_{\mathrm{Abs}}\right)$ represents more serious sediment of CWNFs after 12 hours and vice versa represents the better suspension performance of CWNFs:

$$
R_{\mathrm{Abs}}=\left[\frac{\left(\mathrm{Abs}_{i}-\mathrm{Abs}_{12 \mathrm{hr}}\right)}{\mathrm{Abs}_{i}}\right] \times 100 \% .
$$




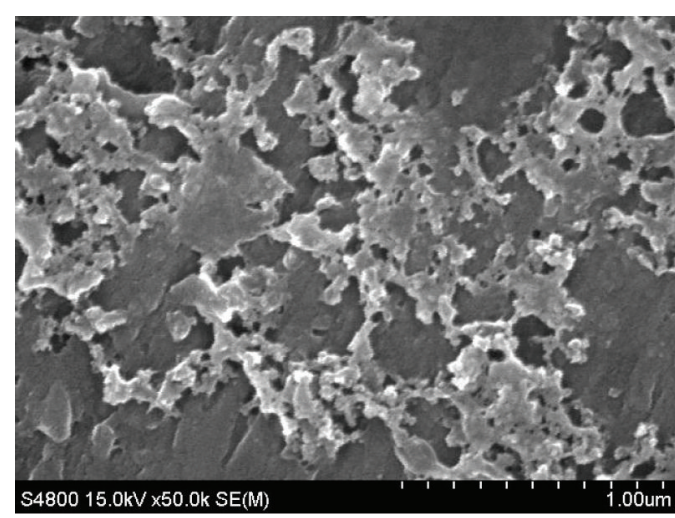

(a)

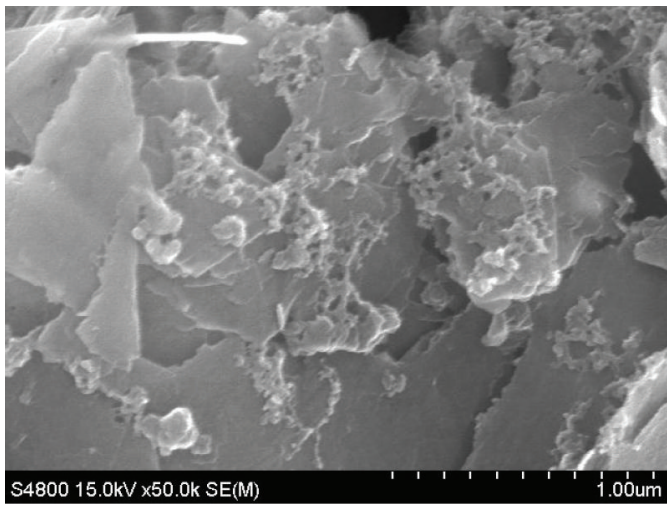

(c)

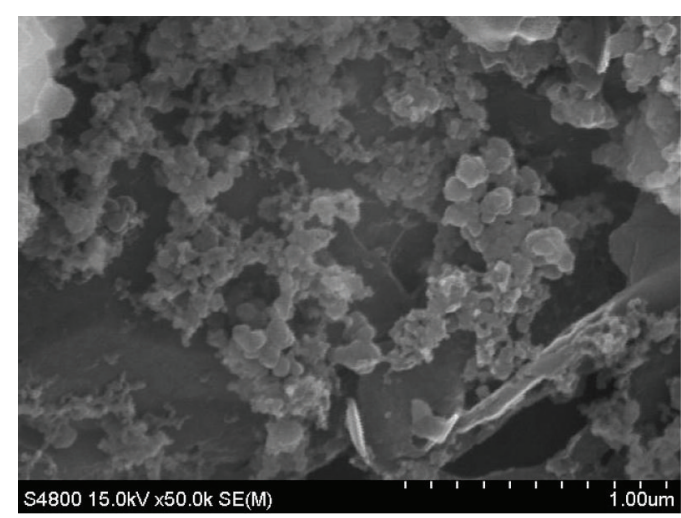

(b)

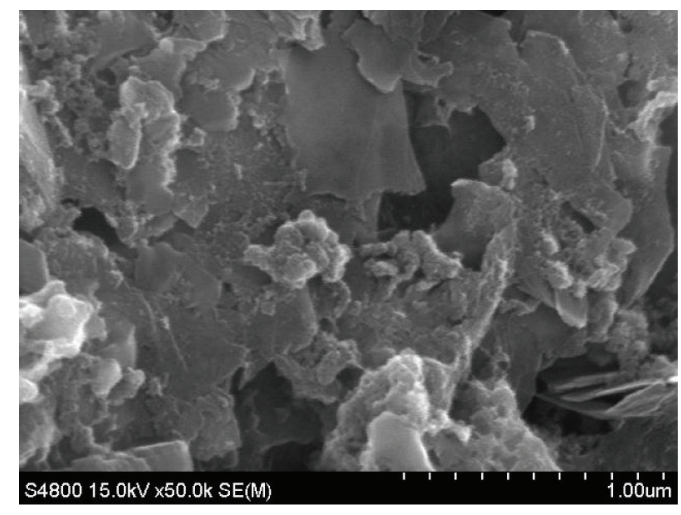

(d)

FIGURE 2: FESEM images of the nanocarbon: (a) $700^{\circ} \mathrm{C}$, (b) $800^{\circ} \mathrm{C}$, (c) $900^{\circ} \mathrm{C}$, and (d) $1000^{\circ} \mathrm{C}$.

Particle size/zeta potential analysis is based on a dynamic light scattering method (DLS), which can simultaneously measure the particle size and zeta potential of the nanocarbon dispersed in a base liquid to determine the suspension performance.

3.5. Measurement of Other Fundamental Characteristics. The thermal conductivity, viscosity, and density of the CWNFs were measured by using a thermal properties analyzer (KD-2 Pro, Decagon Devices, USA) with an accuracy of $5.0 \%$, a sonic viscometer (T15-3, Hydramotion, England) with an accuracy of $\pm 1.0 \%$, and a liquid density meter (DA-130N, KEM, Japan) with an accuracy of $\pm 0.001 \mathrm{~g} / \mathrm{mL}$ in an isothermal unit (P20, YSC, Taiwan) at $25^{\circ} \mathrm{C}$. These experiments were repeated 10 times, and the 6 closest values were averaged as the test value to reduce experimental deviation. The specific heat of the CWNFs was measured using a differential scanning calorimeter (DSC, Q20, TA, USA) with an accuracy of $\pm 1.0 \%$ and a mechanical refrigeration system (RCS40, TA, USA) in a high-purity nitrogen $(5 \mathrm{~N})$ atmosphere. The specific-heat test method was a standard reference approach, and the specific heat of the standard reference (pure water) was obtained from the ASHRAE handbook [47]. The experimental temperature range was $10-40^{\circ} \mathrm{C}$, and the heating rate was $10^{\circ} \mathrm{C} / \mathrm{min}$. The specific heat was calculated at $25^{\circ} \mathrm{C}$. The specific heat of the CWNFs was calculated three times, and the data were averaged as the experimental specific-heat value of the CWNFs.
3.6. Data Analysis. The experimental results obtained with the base liquid (water) were used as baseline values $\left(D_{w}\right)$ to enable an easy comparison of the experimental data after changing the CWNFs $\left(D_{\mathrm{CWNF}}\right)$. The experimental data obtained with the CWNFs were compared with the baseline values. The differences before and after adding the nanocarbon to the water are presented in percentage $(R)$ and calculated as follows:

$$
R=\left[\frac{\left(D_{\mathrm{CWNFs}}-D_{w}\right)}{D_{w}}\right] \times 100 \% .
$$

\section{Results and Discussion}

Figures 2 and 3 show the FESEM and TEM images of the nanocarbons of the CWNFs at different process temperature, respectively. Overall, a lower temperature in the graphite rod module produced solids with a smaller size. By contrast, increasing the temperature intensified the thermal expansion and rupture of the graphite rod, producing flakes and large solids. The thickness of these flake-like solid materials can reach the nanoscale, and a large aspect ratio can be obtained. Furthermore, Figure 3 shows that the RWAS produced a small amount of CNTs (indicated by red arrows). The RWAS can produce additional CNTs through repeating heating and cooling. The FESEM and TEM images only show the local morphology and size of the samples; therefore, the DLS 


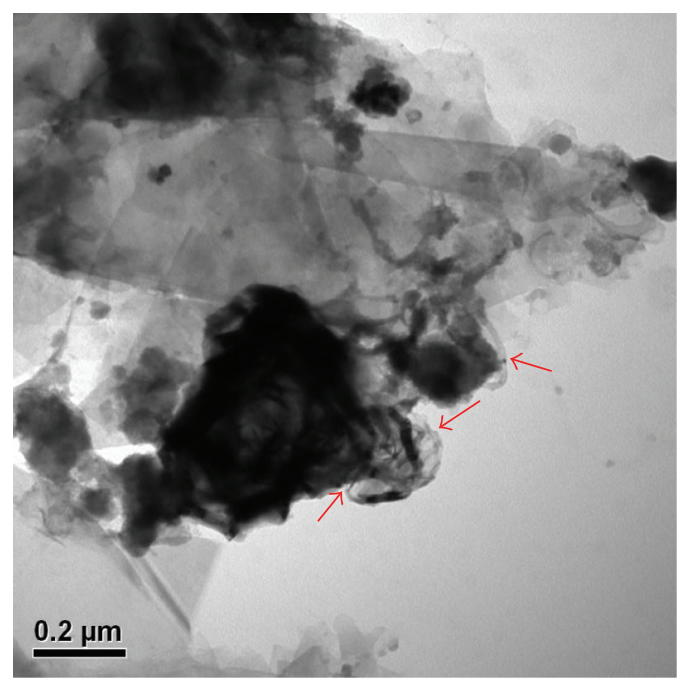

(a)

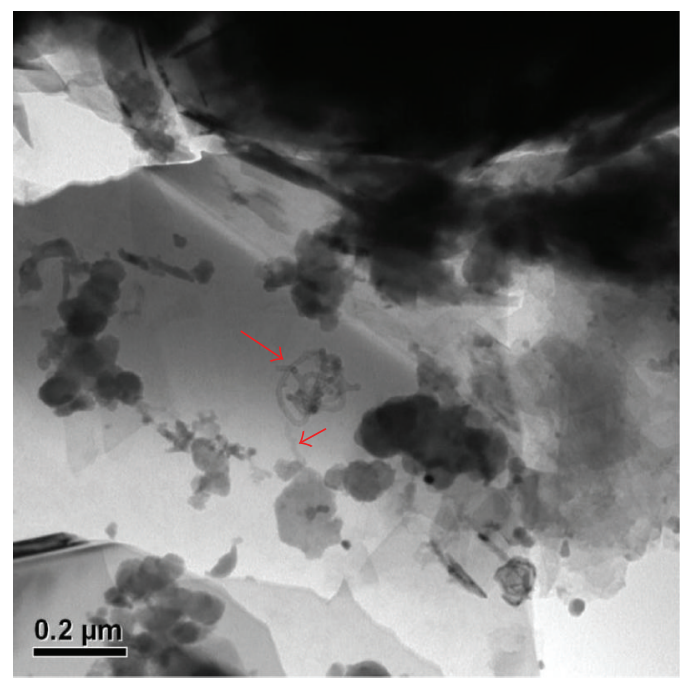

(c)

FIGURE 3: TEM images of the nanocarbon: (a) $700^{\circ} \mathrm{C}$, (b) $800^{\circ} \mathrm{C}$, (c) $900^{\circ} \mathrm{C}$, and (d) $1000^{\circ} \mathrm{C}$.

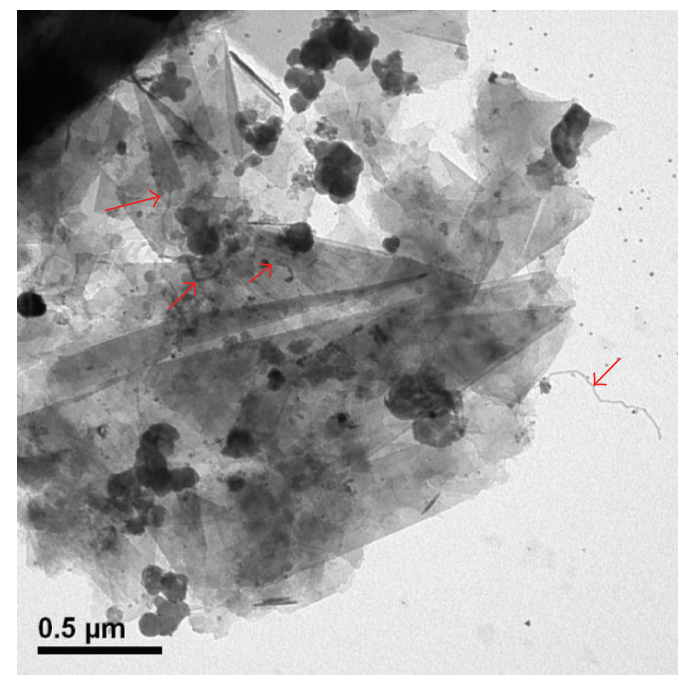

(b)

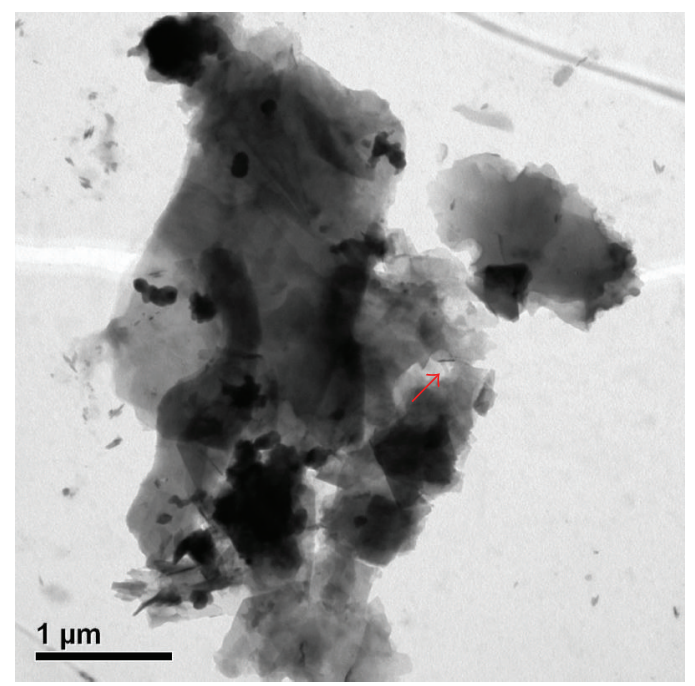

(d) particle size analyzer will be used to confirm the average size of the particles suspended in the CWNFs in a follow-up study.

Figure 4 displays the Raman spectra of the nanocarbons for different process temperature. Two well-defined peaks (called D and G peaks) can be seen in the first-order Raman spectra at approximately 1303 and $1552 \mathrm{~cm}^{-1}$, respectively [48-50]. The $\mathrm{E}_{2 \mathrm{~g}}$ vibration mode, which is the relative motion between two $\mathrm{sp}^{2}$ carbon atoms, produces the $\mathrm{G}$ peak. The $\mathrm{D}$ peak results from the $A_{1 g}$ ring breathing mode; this mode is symmetrically forbidden in perfect graphite. A high $\mathrm{D}$ peak indicates that the nanocarbon has a relatively poor graphitic structure [51]. The intensity of the $\mathrm{D}$ and $\mathrm{G}$ peaks in Figure 4 changed a little in different corresponding process temperatures, indicating that the four samples have similar carbon structures. The $\mathrm{G}$ peak of Raman spectra from the standard value $\left(1580 \mathrm{~cm}^{-1}\right)$ shifted to the $1550 \mathrm{~cm}^{-1}$, and the $I_{\mathrm{D}} / I_{\mathrm{G}}$ of the samples were approximately $0.76,0.60,0.52$, and
0.63 , depending on the heating temperature of the graphite rod module, indicating that the structure of the nanocarbon was a mixture of nanocrystalline graphite and amorphous carbon [48].

Figure 5 displays the XRD patterns of the nanocarbons for different process temperatures. From Figure 5, we can find that the nanocarbons at process temperature of 800 and $900^{\circ} \mathrm{C}$ have a higher diffraction peak around $2 \theta=26.5^{\circ}$, and the nanocarbons at process temperature at 700 and $1000^{\circ} \mathrm{C}$ have relatively weak diffraction peak in this angle. Via JCPDF standard pattern (PDF \# 897213), we confirm that the nanocarbons belong to hexagonal system of graphite-2H [52]. However, except the diffraction peak (002) of graphite- $2 \mathrm{H}$ is more obvious, the other diffraction peaks of graphite- $2 \mathrm{H}$ are quite weak. Therefore, the nanocarbons should be a mixture of graphite- $2 \mathrm{H}$ and amorphous carbon. The test results of XRD are consistent with the test results of Raman spectra. 

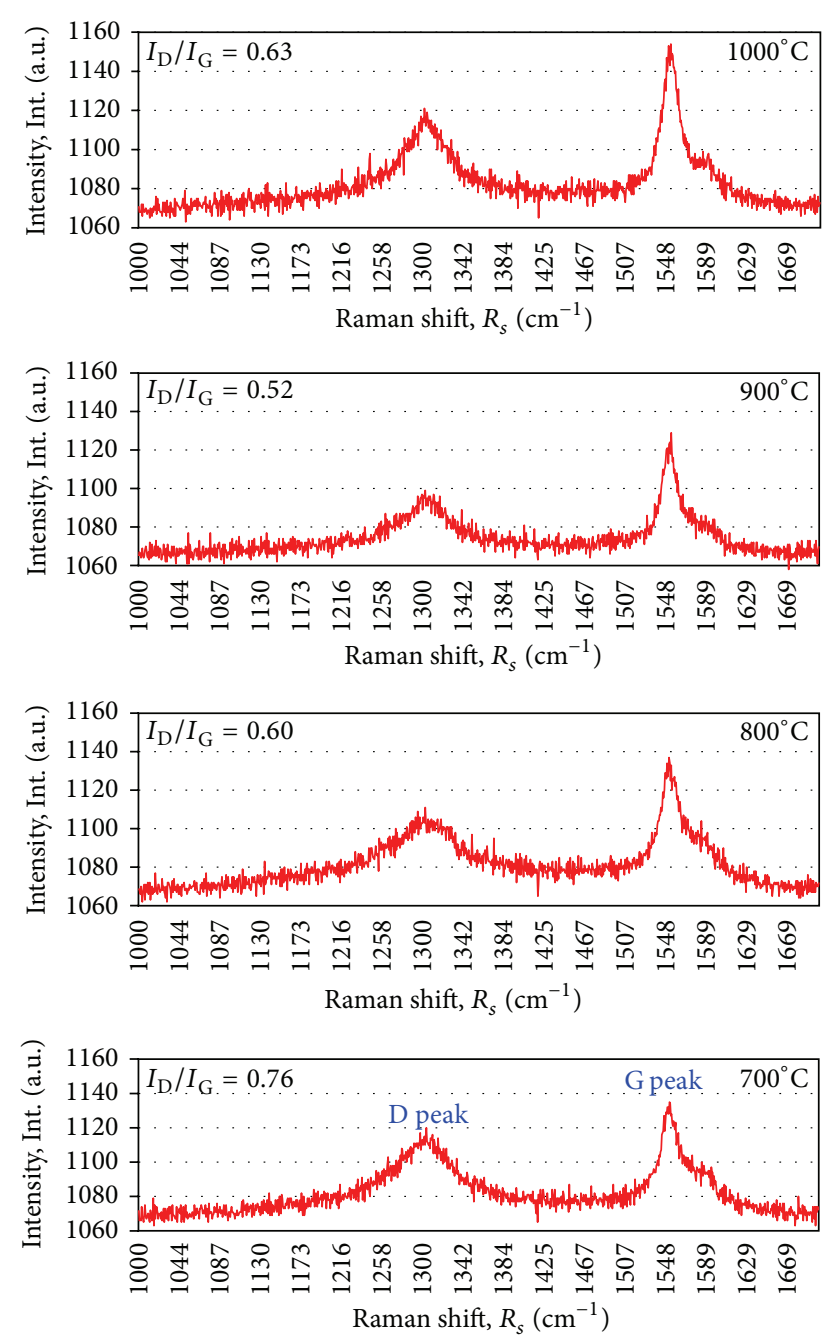

FigURE 4: Raman spectra of the nanocarbon at different process temperatures.

Figure 6 shows the transmittance and absorbance of the CWNFs at different process temperature. For all samples, the transmittance and absorbance curves obtained at different wavelengths exhibited similar trends but had different values. This indicated that all the CWNFs had the same optical characteristics, which is proportional to their concentrations. The results show that the concentration of the CWNFs increased as the process temperature increased. The transmittance and absorbance of CWNFs exhibited similar proportional to their concentrations in those wavelengths, so we used the wavelength of $800 \mathrm{~nm}$ to implement the subsequent concentration and suspension performance analysis.

Figure 7 shows the results of the concentration analysis of the CWNFs at different process temperature by using the weighing method. The graphite rod module was heated at $700,800,900$, and $1000^{\circ} \mathrm{C}$ to produce CWNF concentrations of $0.0190,0.0325,0.0405$, and $0.0760 \mathrm{wt} . \%$, respectively. The experimental results show that the concentration of the CWNFs increased as the process temperature increased. This occurred mainly because a higher temperature difference
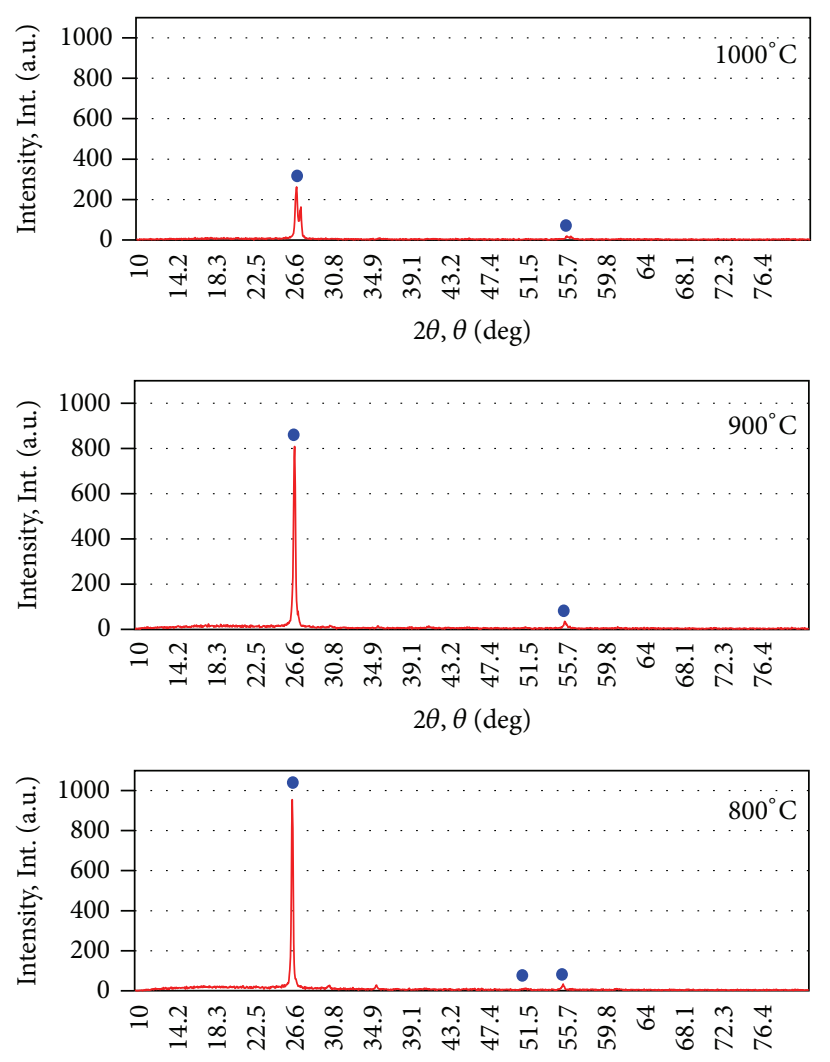

$2 \theta, \theta(\mathrm{deg})$

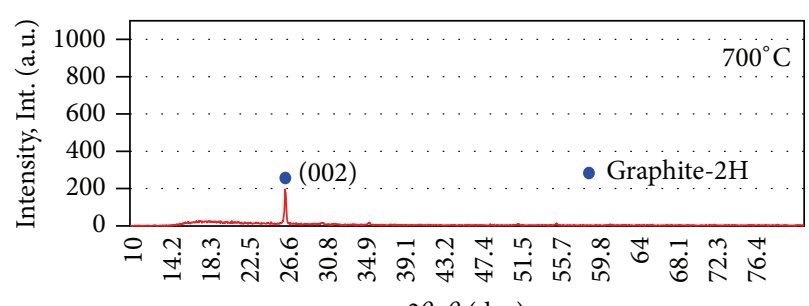

FIGURE 5: XRD patterns of the nanocarbon at different process temperatures.

between heating and cooling results in stronger expansion and disintegration on the graphite rod surface, generating a higher production rate; however, it can also cause a large particle size and uneven nanocarbon distribution. The weighing method involves a long testing time and complex procedures. Therefore, a spectrometer was used to test the absorbance of each sample at $800 \mathrm{~nm}$, and the results were compared with those of the weighing method. The relationship between the absorbance results and weighing method results can facilitate the quantitative analysis of CWNFs that could be manufactured using RWAS in the future. Figure 8 shows the linear relationship between the weight fraction and the absorbance of each CWNF; this relationship can be expressed as the following equation:

$$
\omega=0.0665 \mathrm{Abs}-0.0136 \text {. }
$$

Figure 9 shows an actual photograph of the experimental results of the static position method for CWNFs at different 


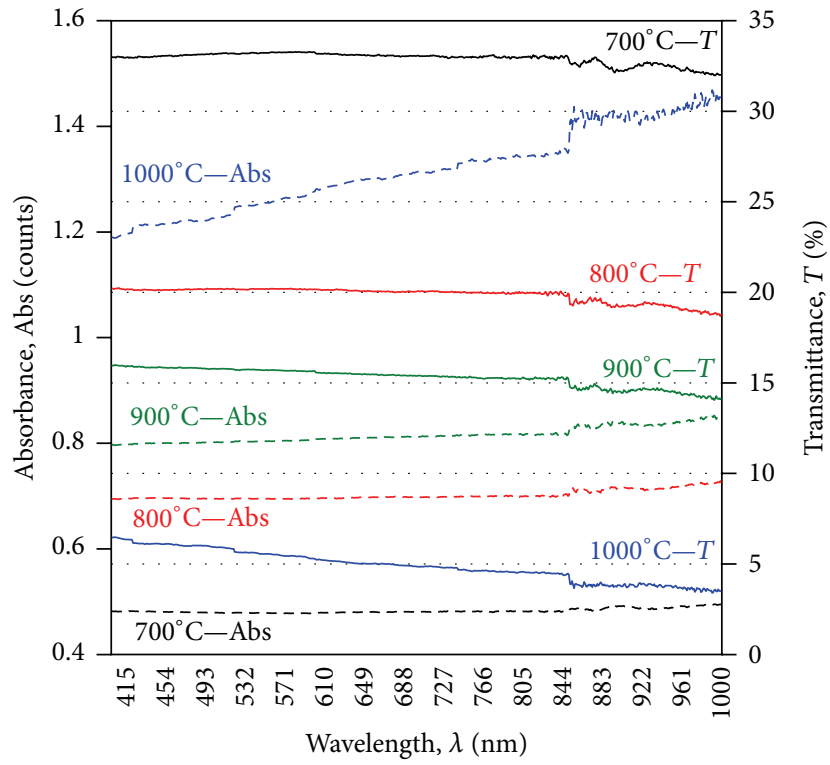

FIGURE 6: Transmittance and absorbance of the CWNFs at different process temperatures.

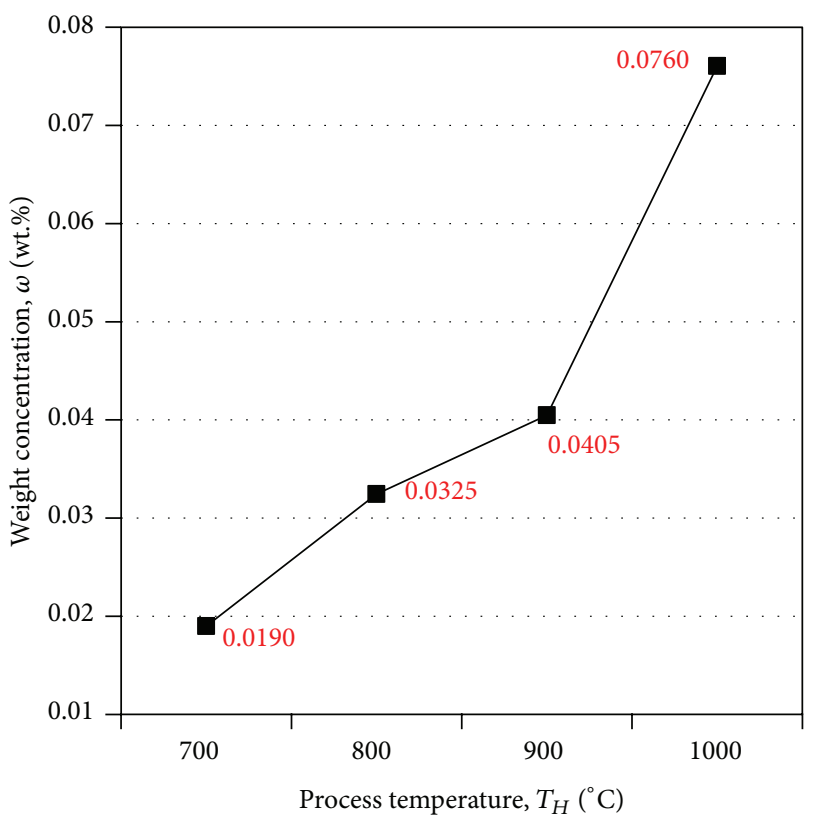

Figure 7: Concentrations of the CWNFs determined using the weighing method at different process temperatures.

process parameters. Adding dispersant effectively enhanced the suspension performance of the CWNFs; a dispersant concentration above $0.2 \mathrm{wt}$ \% substantially improved suspension performance. Figure 10 displays the absorbance $(800 \mathrm{~nm})$ of the CWNFs containing different dispersant concentrations. The increase in dispersant concentration resulted in an increase in the absorbance of the samples. To quantify the results of the static position method, we tested the absorbance of the samples at $800 \mathrm{~nm}$. The samples were statically positioned for 12 hours to analyze the suspension performance

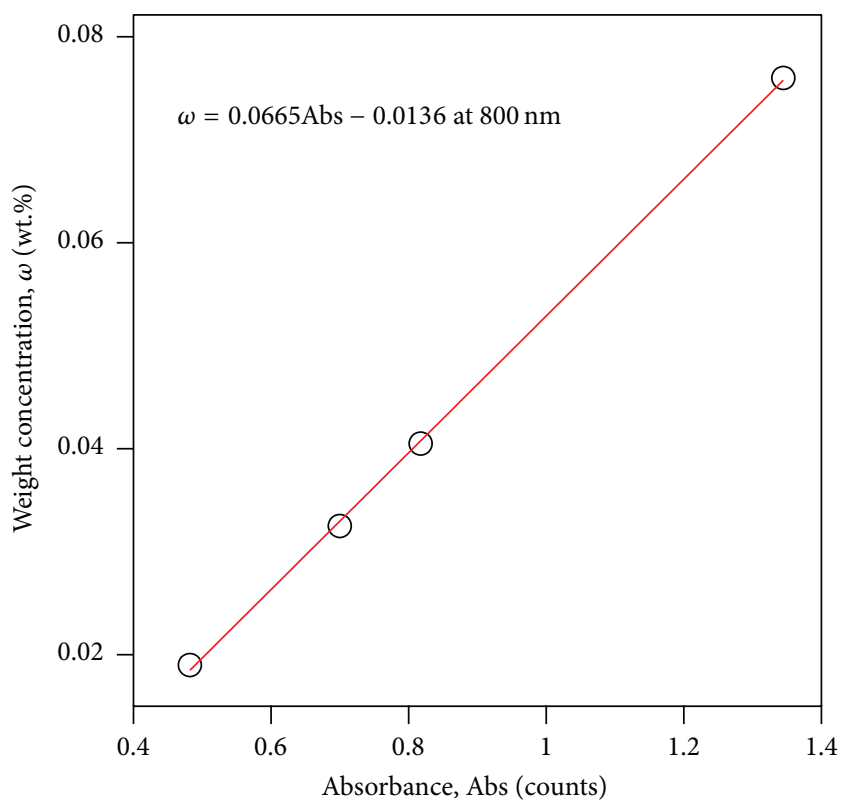

FIGURE 8: Relationship between the weight fraction and absorbance of the CWNFs.

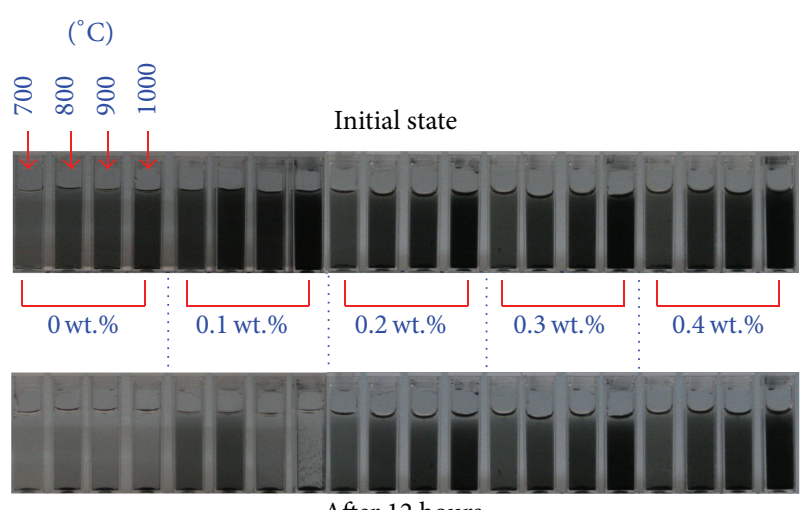

FIGURE 9: Photograph of experimental results for the static position method.

$\left(R_{\text {Abs }}\right)$ of CWNFs by using (1) in Figure 11. The dispersant added to the CWNFs substantially improved the suspension performance. However, suspension performance had a nonlinear relationship with dispersant concentration. The benefits of adding dispersant to improve the suspension performance diminished when the concentration of dispersant was above 0.2 wt. $\%$.

Figure 12 shows the average suspended particle sizes of each sample at different process parameters. The results show that the nanocarbon size was greater when the process temperature was higher. The smallest average suspended particle size was approximately $350 \mathrm{~nm}$. However, dispersant addition tended to increase the average size of the suspended particles. This occurred because larger particles settled during the test procedure when dispersant were not added; therefore, the test results only show smaller particles of the CWNFs. Because 


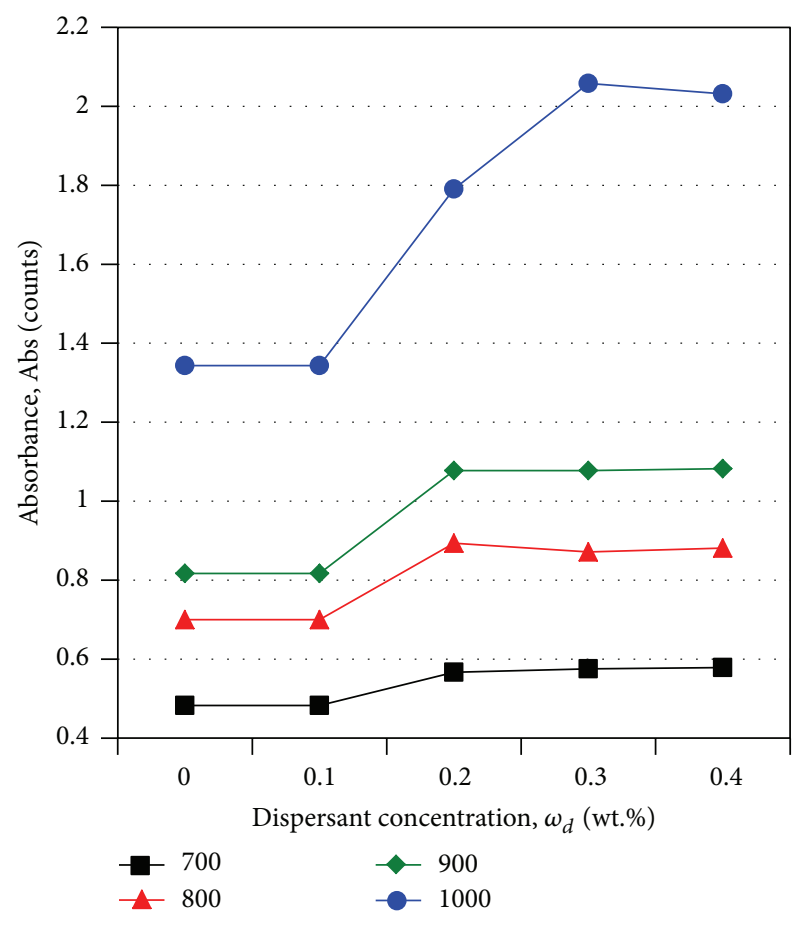

Figure 10: Absorbance of the CWNFs at different process temperature and dispersant concentrations.

dispersant addition enhanced the suspension performance of the CWNFs and reduced the sedimentation of large particles during the test procedure, the average suspended particle size increased considerably. In addition, the samples produced by process temperature in the range of $700-900^{\circ} \mathrm{C}$ did not exhibit a considerable increase in the average size of the suspended particles after adding dispersant, suggesting that the particles were relatively small particle and the nanocarbon was well distributed in this range of heating temperature. In addition, a DLS particle size analyzer cannot be used to measure the average suspended particle size of samples with poor suspension performance because this device generates a large experimental deviation.

Figure 13 shows the results of the zeta potential $\left(V_{z}\right)$ test of the samples at different process parameters. The $V_{z}$ of the CWNFs changed from negative to positive potential after adding dispersant because the added dispersant was cationic. The highest $V_{z}$ (approximately $38 \mathrm{mV}$ ) was obtained by adding $0.2 \mathrm{wt} . \%$ of dispersant and heating the graphite rod module at $1000^{\circ} \mathrm{C}$.

The experimental data of the base liquid (water) is shown in Table 1. The ratio in Figures 14 to 17 can be converted into the actual value by using the data in Table 1 and applying (2).

Figure 14 shows the thermal conductivity ratio of the CWNFs at different process parameters. The CWNFs with higher nanocarbon concentrations exhibited a higher thermal conductivity. However, a high dispersant concentration resulted in a low thermal conductivity for the CWNFs. This occurred because the nanocarbon suspended in the CWNFs had a higher thermal conductivity than that of water; however, the thermal conductivity of the dispersant

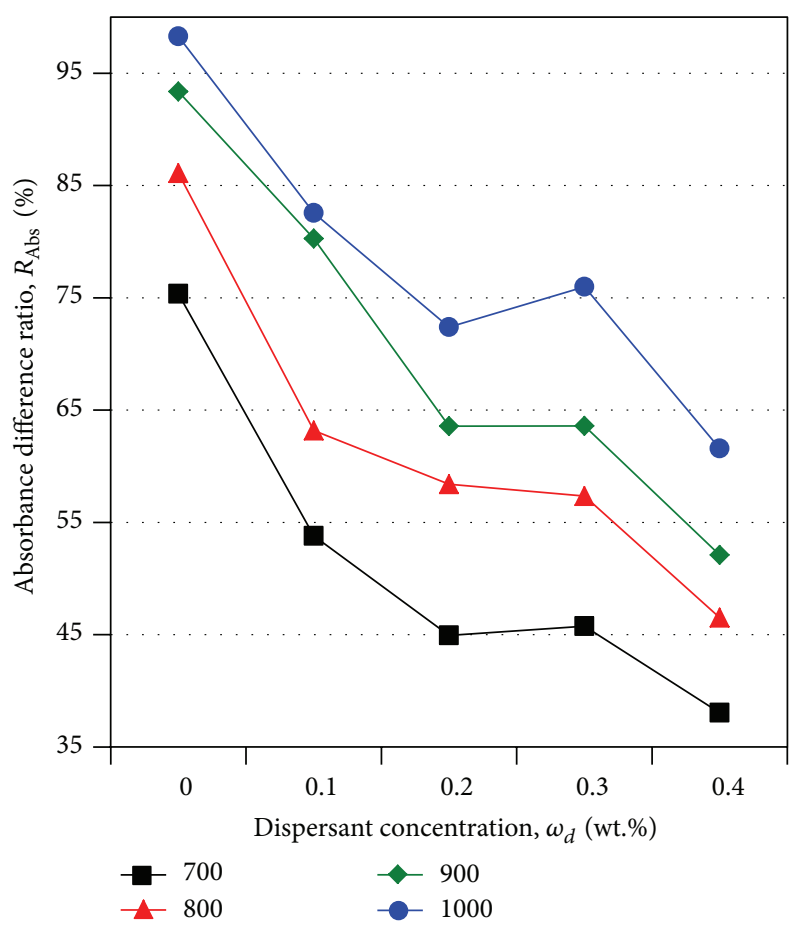

FIGURE 11: Absorbance difference ratio among the CWNFs for the static position method at different process temperature and dispersant concentrations.

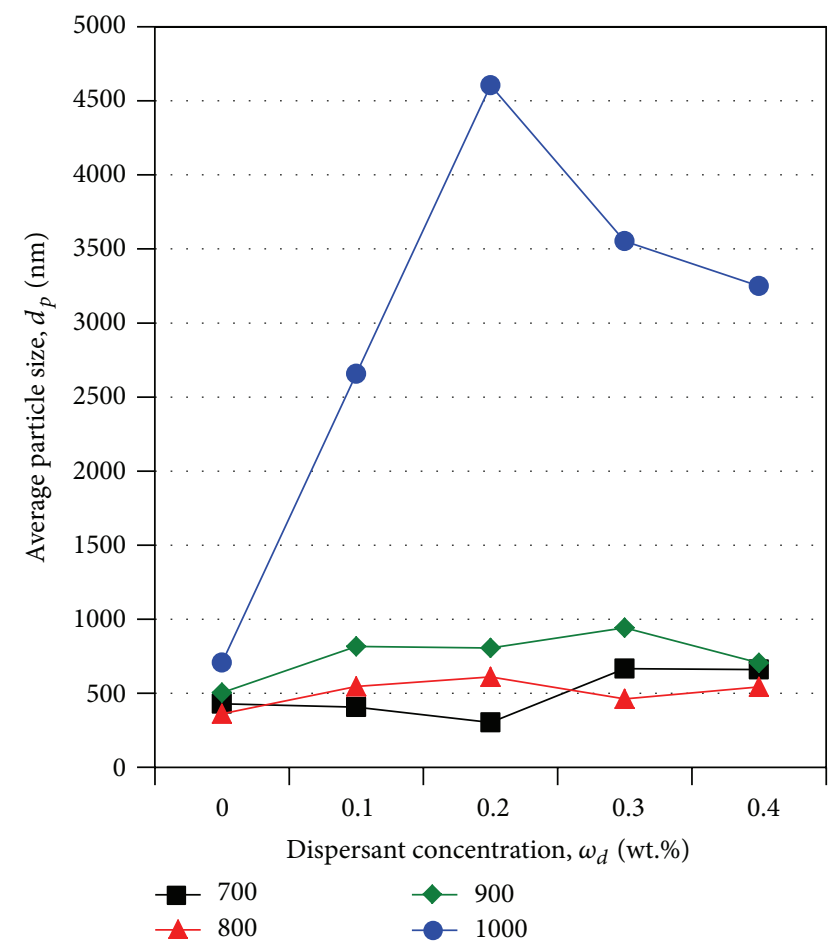

FIgURE 12: Average suspended particle size of the CWNFs at different process temperature and dispersant concentrations. 


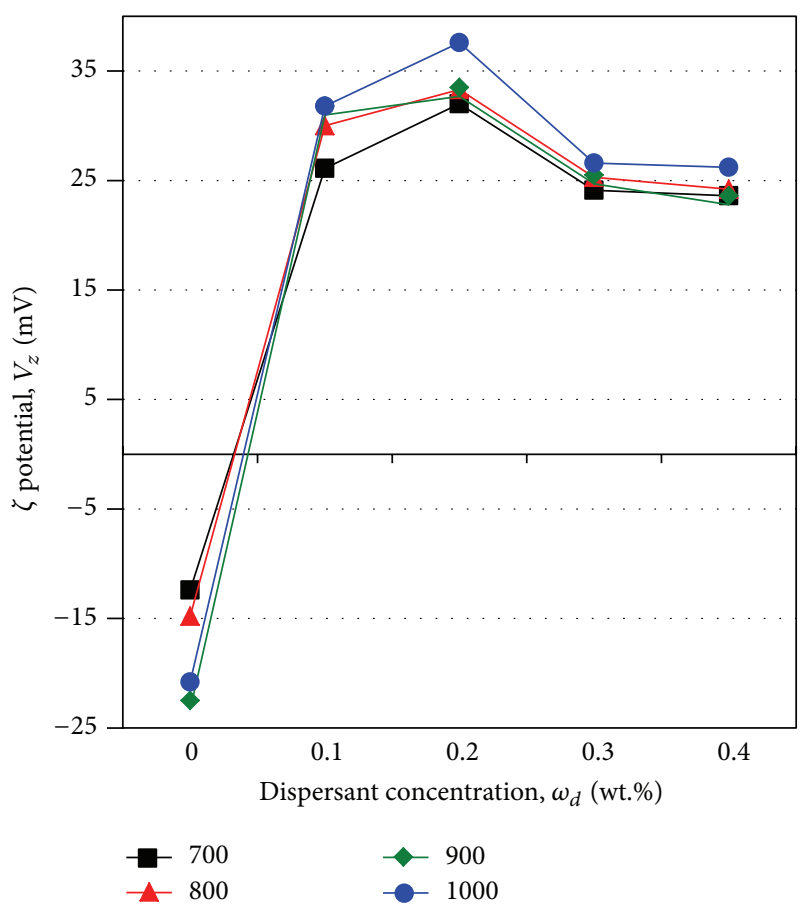

Figure 13: Zeta potential of the CWNFs at different process temperature and dispersant concentrations.

TABLE 1: Experimental data of water for baseline.

\begin{tabular}{lcc}
\hline Items & Units & Value \\
\hline Thermal conductivity & $\mathrm{W} / \mathrm{m} \cdot{ }^{\circ} \mathrm{C}$ & 0.604 \\
Viscosity & $\mathrm{mPa} \cdot \mathrm{s}$ & 0.8 \\
Density & $\mathrm{kg} / \mathrm{m}^{3}$ & 997.3 \\
Specific heat & $\mathrm{kJ} / \mathrm{kg} \cdot{ }^{\circ} \mathrm{C}$ & $4.183^{\mathrm{a}}$ \\
\hline
\end{tabular}

${ }^{\mathrm{a}}$ The specific heat of water refer ASHRAE handbook [47].

was lower than that of water. Nevertheless, a high thermal conductivity of the CWNFs can be achieved by increasing the concentration of nanocarbon. The thermal conductivity of the CWNFs increased $9.53 \%$ at the highest concentration of nanocarbon, without dispersant. The thermal conductivity of the CWNFs decreased $12.19 \%$ at the lowest concentration of nanocarbon and a dispersant concentration of $0.4 \mathrm{wt} . \%$.

Figure 15 displays the viscosity of the CWNFs increased as the concentration of nanocarbon and dispersant increased. The dispersant had an obvious influence on the viscosity of the CWNFs. The viscosity of the CWNFs increased by $45.0 \%$ at the highest concentration of nanocarbon and dispersant.

Figure 16 shows that the density of the CWNFs increased as the concentration of nanocarbon and dispersant increased, but the effect of these two factors on the density of the CWNFs was not obvious. This may be explained by the low concentration of nanocarbon and the similarity between the density of the dispersant and that of water. The density of the CWNFs increased $0.19 \%$ when compared with water at the highest concentration of nanocarbon and dispersant.

Figure 17 shows that the CWNFs with high nanocarbon concentrations had low specific heat; however, increasing

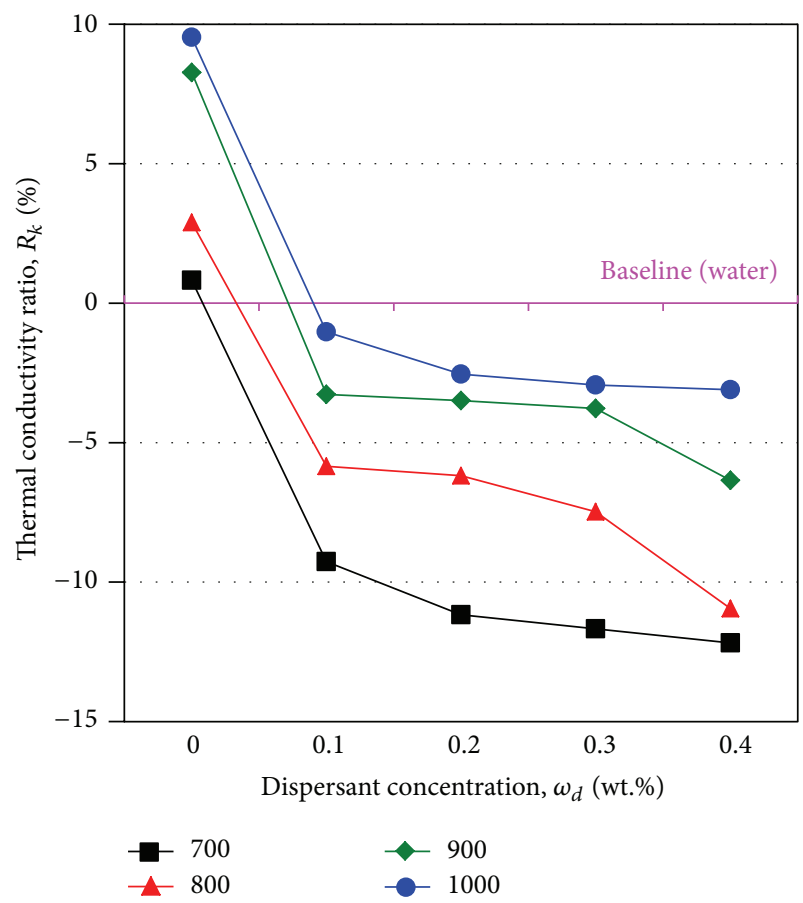

FIGURE 14: Thermal conductivity ratios of the CWNFs at different process temperature and dispersant concentrations.

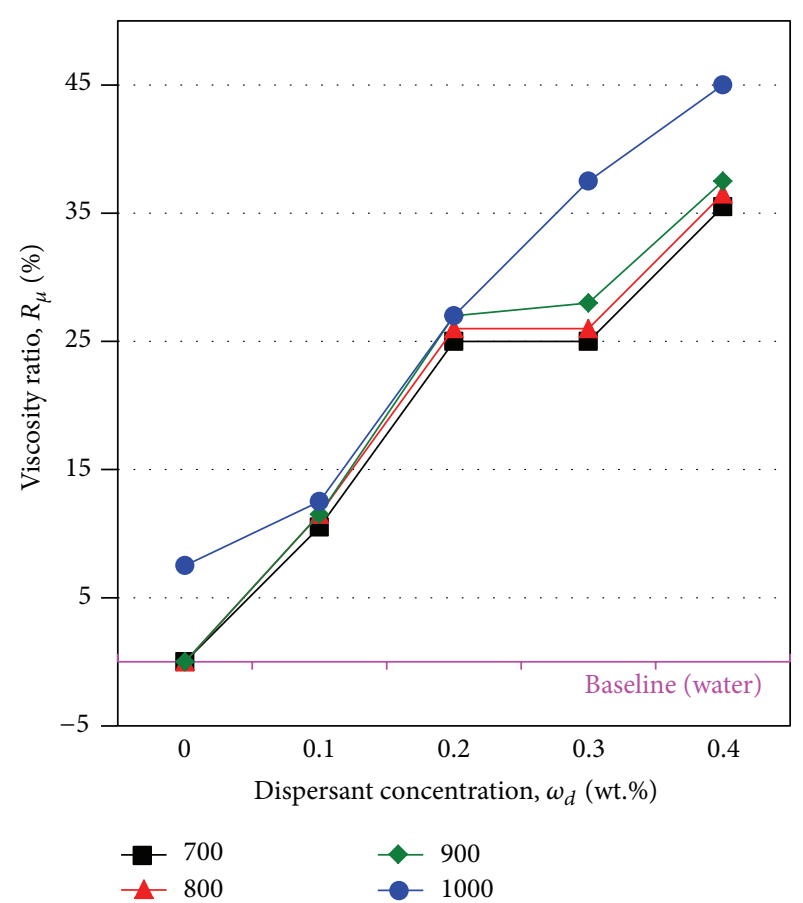

FIGURE 15: Viscosity ratios of the CWNFs at different process temperature and dispersant concentrations.

dispersant concentration increased the specific heat of the CWNFs. This occurred because the specific heat of the nanocarbon in the CWNFs was lower than that of water, and the specific heat of the dispersant was higher than that of 


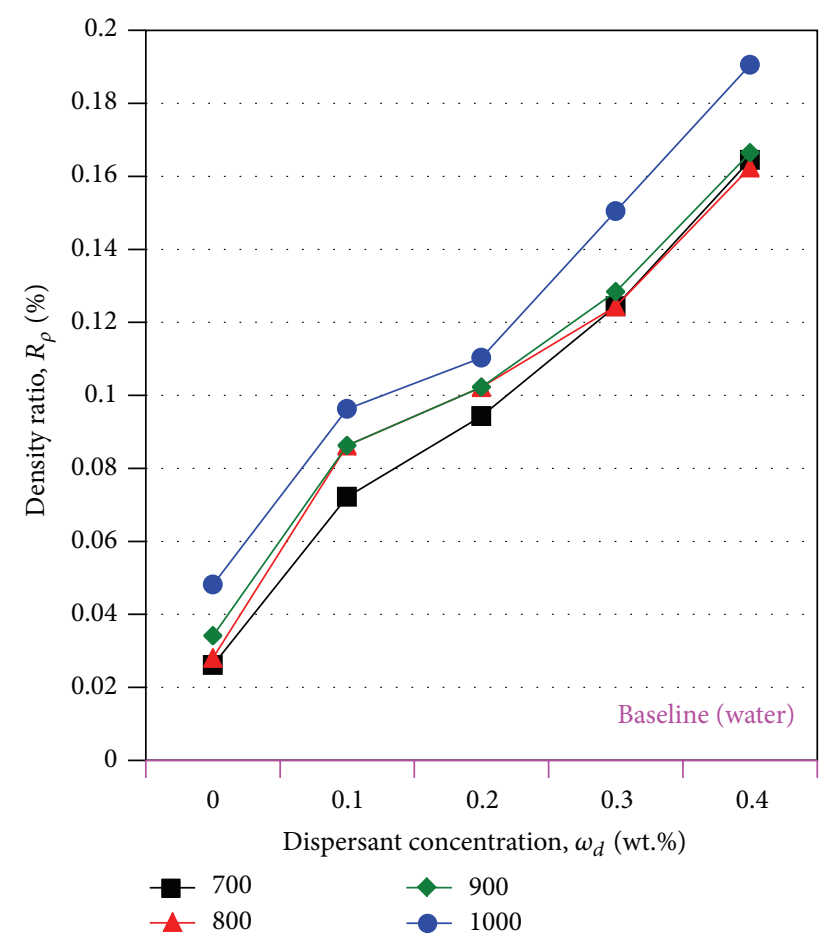

Figure 16: Density ratios of the CWNFs at different process temperature and dispersant concentrations.

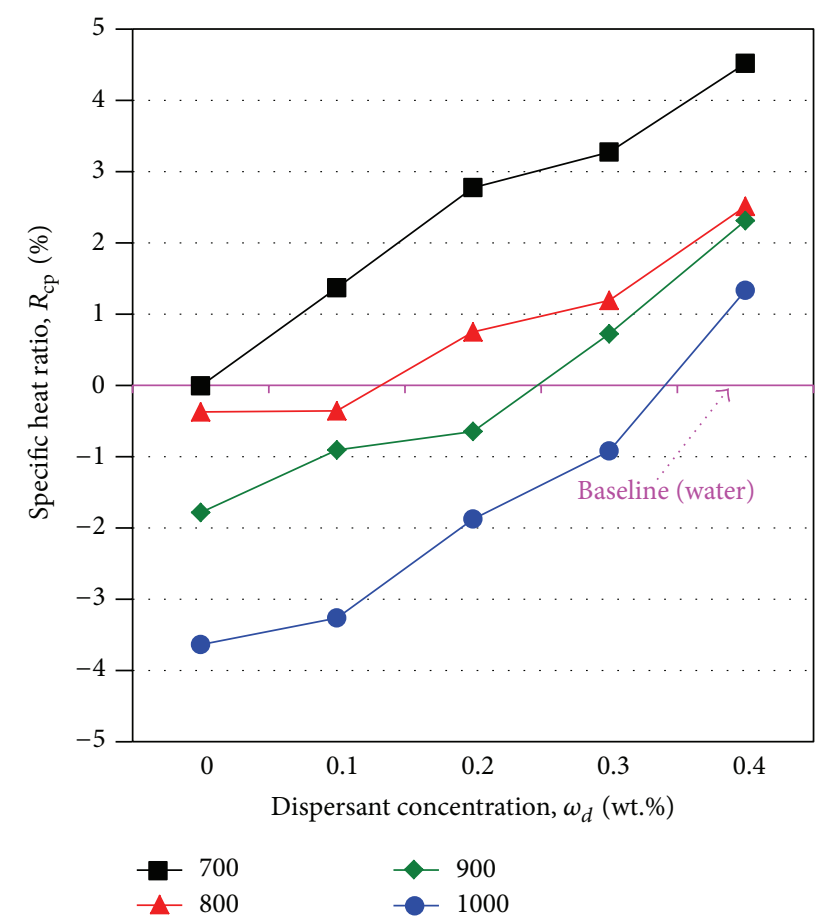

FIgURE 17: Specific heat ratios of the CWNFs at different process temperature and dispersant concentrations.

water. The specific heat of the CWNFs decreased by $3.64 \%$ at the highest concentration of nanocarbon, without dispersant. The specific heat of the CWNFs increased by $4.52 \%$ at the lowest concentration of nanocarbon when the dispersant concentration was $0.4 \mathrm{wt} . \%$.

\section{Conclusions}

In this study, we used a RWAS to fabricate CWNFs in a onestep synthesis process. The CWNFs were manufactured by heating graphite rods at different temperatures. The characteristics of the CWNFs and suspended nanocarbon were examined using suitable instruments and test methods. The findings of this study are summarized as follows.

(1) The structure of the nanocarbon was a mixture of nanocrystalline graphite and amorphous carbon, which was determined using Raman spectroscopy and XRD.

(2) Heating the graphite rod module at a higher temperature resulted in a higher production rate and greater nanocarbon particle size.

(3) The DLS particle size analyzer is not suitable for measuring the average suspended particle size of samples with poor suspension performance because it generates considerable experimental deviation.

(4) Adding dispersant can improve the suspension performance of the CWNFs, but it can also increase their viscosity, density, and specific heat and decrease their thermal conductivity.

(5) The optimal combination of the process temperature range and dispersant concentration was 800 to $900^{\circ} \mathrm{C}$ and $0.2 \mathrm{wt} . \%$, respectively, based on the production rate, suspension performance, and fundamental characteristics of the CWNFs.

\section{Conflict of Interests}

The authors declare that there is no conflict of interests regarding the publication of this paper.

\section{Acknowledgment}

The authors would like to thank National Science Council of the Republic of China (Taiwan) for their financial support to this research under Contract no. NSC 101-2221-E-003-011MY2.

\section{References}

[1] S. U. S. Choi, "Enhancing thermal conductivity of fluids with nanoparticles," in Developments and Applications of Non-Newtonian Flows, D. A. Siginer and H. P. Wang, Eds., vol. 231, pp. 99-105, ASME FED, 1995.

[2] Y. J. Hwang, Y. C. Ahn, H. S. Shin et al., "Investigation on characteristics of thermal conductivity enhancement of nanofluids," Current Applied Physics, vol. 6, no. 6, pp. 1068-1071, 2006.

[3] Y. Hwang, J. K. Lee, C. H. Lee et al., "Stability and thermal conductivity characteristics of nanofluids," Thermochimica Acta, vol. 455, no. 1-2, pp. 70-74, 2007. 
[4] D. Zhu, X. Li, N. Wang, X. Wang, J. Gao, and H. Li, "Dispersion behavior and thermal conductivity characteristics of $\mathrm{Al}_{2} \mathrm{O}_{3}$ $\mathrm{H}_{2} \mathrm{O}$ nanofluids," Current Applied Physics, vol. 9, no. 1, pp. 131139, 2009.

[5] T. X. Phuoc, M. Massoudi, and R.-H. Chen, "Viscosity and thermal conductivity of nanofluids containing multi-walled carbon nanotubes stabilized by chitosan," International Journal of Thermal Sciences, vol. 50, no. 1, pp. 12-18, 2011.

[6] T.-P. Teng, C.-M. Cheng, and F.-Y. Pai, "Preparation and characterization of carbon nanofluid by a plasma arc nanoparticles synthesis system," Nanoscale Research Letters, vol. 6, article 293, 2011.

[7] Z. Meng, D. Wu, L. Wang, H. Zhu, and Q. Li, "Carbon nanotube glycol nanofluids: photo-thermal properties, thermalconductivities and rheological behavior," Particuology, vol.10, no. 5, pp. 614-618, 2012.

[8] K. S. Suganthi and K. S. Rajan, "Temperature induced changes in $\mathrm{ZnO}$-water nanofluid: zeta potential, size distribution and viscosity profiles," International Journal of Heat and Mass Transfer, vol. 55, no. 25-26, pp. 7969-7980, 2012.

[9] S. Harish, K. Ishikawa, E. Einarsson et al., "Enhanced thermal conductivity of ethylene glycol with single-walled carbon nanotube inclusions," International Journal of Heat and Mass Transfer, vol. 55, no. 13, pp. 3885-3890, 2012.

[10] T. P. Teng, "Thermal conductivity and phase-change properties of aqueous alumina nanofluid," Energy Conversion and Management, vol. 67, pp. 369-375, 2013.

[11] S. M. Fotukian and M. Nasr Esfahany, "Experimental investigation of turbulent convective heat transfer of dilute $\gamma-\mathrm{Al}_{2} \mathrm{O}_{3} /$ water nanofluid inside a circular tube," International Journal of Heat and Fluid Flow, vol. 31, no. 4, pp. 606-612, 2010.

[12] S. M. Fotukian and M. Nasr Esfahany, "Experimental study of turbulent convective heat transfer and pressure drop of dilute $\mathrm{CuO} /$ water nanofluid inside a circular tube," International Communications in Heat and Mass Transfer, vol. 37, no. 2, pp. 214219, 2010.

[13] A. R. Sajadi and M. H. Kazemi, "Investigation of turbulent convective heat transfer and pressure drop of $\mathrm{TiO}_{2} /$ water nanofluid in circular tube," International Communications in Heat and Mass Transfer, vol. 38, no. 10, pp. 1474-1478, 2011.

[14] L. Syam Sundar, M. T. Naik, K. V. Sharma, M. K. Singh, and T. C. Siva Reddy, "Experimental investigation of forced convection heat transfer and friction factor in a tube with $\mathrm{Fe}_{3} \mathrm{O}_{4}$ magnetic nanofluid," Experimental Thermal and Fluid Science, vol. 37, pp. 65-71, 2012.

[15] K. Wongcharee and S. Eiamsa-ard, "Heat transfer enhancement by using $\mathrm{CuO} /$ water nanofluid in corrugated tube equipped with twisted tape," International Communications in Heat and Mass Transfer, vol. 39, no. 2, pp. 251-257, 2012.

[16] W. Duangthongsuk and S. Wongwises, "Heat transfer enhancement and pressure drop characteristics of $\mathrm{TiO}_{2}$-water nanofluid in a double-tube counter flow heat exchanger," International Journal of Heat and Mass Transfer, vol. 52, no. 7-8, pp. 20592067, 2009.

[17] C. J. Ho, L. C. Wei, and Z. W. Li, "An experimental investigation of forced convective cooling performance of a microchannel heat sink with $\mathrm{Al}_{2} \mathrm{O}_{3}$ /water nanofluid," Applied Thermal Engineering, vol. 30, no. 2-3, pp. 96-103, 2010.

[18] T. Maré, S. Halelfadl, O. Sow, P. Estellé, S. Duret, and F. Bazantay, "Comparison of the thermal performances of two nanofluids at low temperature in a plate heat exchanger," Experimental Thermal and Fluid Science, vol. 35, no. 8, pp. 1535-1543, 2011.
[19] P. Selvakumar and S. Suresh, "Convective performance of $\mathrm{CuO} /$ water nanofluid in an electronic heat sink," Experimental Thermal and Fluid Science, vol. 40, pp. 57-63, 2012.

[20] T.-P. Teng, Y.-H. Hung, T.-C. Teng, and J.-H. Chen, "Performance evaluation on an air-cooled heat exchanger for alumina nanofluid under laminar flow," Nanoscale Research Letters, vol. 6, article 488, 2011.

[21] C. J. Ho and W. C. Chen, "An experimental study on thermal performance of $\mathrm{Al}_{2} \mathrm{O}_{3}$ /water nanofluid in a minichannel heat sink," Applied Thermal Engineering, vol. 50, no. 1, pp. 516-522, 2013.

[22] D. P. Kulkarni, R. S. Vajjha, D. K. Das, and D. Oliva, "Application of aluminum oxide nanofluids in diesel electric generator as jacket water coolant," Applied Thermal Engineering, vol. 28, no. 14-15, pp. 1774-1781, 2008.

[23] K. Y. Leong, R. Saidur, S. N. Kazi, and A. H. Mamun, "Performance investigation of an automotive car radiator operated with nanofluid-based coolants (nanofluid as a coolant in a radiator)," Applied Thermal Engineering, vol. 30, no. 17-18, pp. 2685-2692, 2010.

[24] S. M. Peyghambarzadeh, S. H. Hashemabadi, M. Naraki, and Y. Vermahmoudi, "Experimental study of overall heat transfer coefficient in the application of dilute nanofluids in the car radiator," Applied Thermal Engineering, vol. 52, no. 1, pp. 8-16, 2013.

[25] M. Naraki, S. M. Peyghambarzadeh, S. H. Hashemabadi, and Y. Vermahmoudi, "Parametric study of overall heat transfer coefficient of $\mathrm{CuO}$ /water nanofluids in a car radiator," International Journal of Thermal Sciences, vol. 66, pp. 82-90, 2013.

[26] O. Mahian, A. Kianifar, S. A. Kalogirou, I. Pop, and S. Wongwises, "A review of the applications of nanofluids in solar energy," International Journal of Heat and Mass Transfer, vol. 57, no. 2, pp. 582-594, 2013.

[27] J. Y. Jung, E. S. Kim, Y. Nam, and Y. T. Kang, “The study on the critical heat flux and pool boiling heat transfer coefficient of binary nanofluids $\left(\mathrm{H}_{2} \mathrm{O} / \mathrm{LiBr}+\mathrm{Al}_{2} \mathrm{O}_{3}\right)$," International Journal of Refrigeration, vol. 36, no. 3, pp. 1056-1061, 2013.

[28] M. Wagener and B. Günther, "Sputtering on liquids-a versatile process for the production of magnetic suspensions?" Journal of Magnetism and Magnetic Materials, vol. 201, no. 1-3, pp. 41-44, 1999.

[29] Y. Hwang, J.-K. Lee, J.-K. Lee et al., "Production and dispersion stability of nanoparticles in nanofluids," Powder Technology, vol. 186, no. 2, pp. 145-153, 2008.

[30] E. Tamjid and B. H. Guenther, "Rheology and colloidal structure of silver nanoparticles dispersed in diethylene glycol," Powder Technology, vol. 197, no. 1-2, pp. 49-53, 2010.

[31] C.-H. Lo, T.-T. Tsung, and L.-C. Chen, "Shape-controlled synthesis of $\mathrm{Cu}$-based nanofluid using submerged arc nanoparticle synthesis system (SANSS)," Journal of Crystal Growth, vol. 277, no. 1-4, pp. 636-642, 2005.

[32] H. Chang and Y.-C. Chang, "Fabrication of $\mathrm{Al}_{2} \mathrm{O}_{3}$ nanofluid by a plasma arc nanoparticles synthesis system," Journal of Materials Processing Technology, vol. 207, no. 1-3, pp. 193-199, 2008.

[33] G.-J. Lee, C. K. Kim, M. K. Lee, C. K. Rhee, S. Kim, and C. Kim, "Thermal conductivity enhancement of $\mathrm{ZnO}$ nanofluid using a one-step physical method," Thermochimica Acta, vol. 542, pp. 24-27, 2012.

[34] H. J. Kim, I. C. Bang, and J. Onoe, "Characteristic stability of bare $\mathrm{Au}$-water nanofluids fabricated by pulsed laser ablation in liquids," Optics and Lasers in Engineering, vol. 47, no. 5, pp. 532538, 2009. 
[35] F. Barreca, N. Acacia, E. Barletta, D. Spadaro, G. Currò, and F. Neri, "Small size $\mathrm{TiO}_{2}$ nanoparticles prepared by laser ablation in water," Applied Surface Science, vol. 256, no. 21, pp. 6408$6412,2010$.

[36] V. Thongpool, P. Asanithi, and P. Limsuwan, "Synthesis of carbon particles using laser ablation in ethanol," Procedia Engineering, vol. 32, pp. 1054-1060, 2012.

[37] Z. Kang, E. Wang, L. Gao et al., "One-step water-assisted synthesis of high-quality carbon nanotubes directly from graphite," Journal of the American Chemical Society, vol. 125, no. 45, pp. 13652-13653, 2003.

[38] M. Bansal, C. Lal, L. S. Tanwar, and V. Gupta, "Investigation of water-assisted synthesis of high quality carbon nanotubes," Materials Science and Engineering B, vol. 157, no. 1-3, pp. 93-95, 2009.

[39] H.-T. Zhu, Y.-S. Lin, and Y.-S. Yin, "A novel one-step chemical method for preparation of copper nanofluids," Journal of Colloid and Interface Science, vol. 277, no. 1, pp. 100-103, 2004.

[40] S. A. Kumar, K. S. Meenakshi, B. R. V. Narashimhan, S. Srikanth, and G. Arthanareeswaran, "Synthesis and characterization of copper nanofluid by a novel one-step method," Materials Chemistry and Physics, vol. 113, no. 1, pp. 57-62, 2009.

[41] M. Abareshi, E. K. Goharshadi, S. Mojtaba Zebarjad, H. Khandan Fadafan, and A. Youssefi, "Fabrication, characterization and measurement of thermal conductivity of $\mathrm{Fe}_{3} \mathrm{O}_{4}$ nanofluids," Journal of Magnetism and Magnetic Materials, vol. 322, no. 24, pp. 3895-3901, 2010.

[42] G. Yang, Z. Zhang, S. Zhang, L. Yu, and P. Zhang, "Synthesis and characterization of highly stable dispersions of copper nanoparticles by a novel one-pot method," Materials Research Bulletin, vol. 48, no. 4, pp. 1716-1719, 2013.

[43] A. Kosmala, Q. Zhang, R. Wright, and P. Kirby, "Development of high concentrated aqueous silver nanofluid and inkjet printing on ceramic substrates," Materials Chemistry and Physics, vol. 132, no. 2-3, pp. 788-795, 2012.

[44] M. Wan, R. R. Yadav, K. L. Yadav, and S. B. Yadaw, "Synthesis and experimental investigation on thermal conductivity of nanofluids containing functionalized Polyaniline nanofibers," Experimental Thermal and Fluid Science, vol. 41, article 158, 2012.

[45] H. Hezaveh, A. Fazlali, and I. Noshadi, "Synthesis, rheological properties and magnetoviscos effect of $\mathrm{Fe}_{2} \mathrm{O}_{3}$ /paraffin ferrofluids," Journal of the Taiwan Institute of Chemical Engineers, vol. 43, no. 1, pp. 159-164, 2012.

[46] Charming \& Beauty Inc., water-soluble chitosan (C06), http:// www.cabco.com.tw/chinese/Product-2004111482456.html?CID $=1$.

[47] ASHRAE, "Chapter 31 Physical properties of secondary coolants (brines)," in 2009 ASHRAE Handbook-Fundamentals (SI), ASHRAE Inc., 2009.

[48] A. C. Ferrari and J. Robertson, "Interpretation of Raman spectra of disordered and amorphous carbon," Physical Review B, vol. 61, no. 20, pp. 14095-14107, 2000.

[49] A. C. Ferrari and J. Robertson, "Resonant raman spectroscopy of disordered, amorphous, and diamondlike carbon," Physical Review B, vol. 64, no. 7, Article ID 075414, 13 pages, 2001.

[50] S. Rodrigues, M. Marques, I. Suárez-Ruiz, I. Camean, D. Flores, and B. Kwiecinska, "Microstructural investigations of natural and synthetic graphites and semi-graphites," International Journal of Coal Geology, vol. 111, pp. 67-79, 2013.

[51] T. Xing, L. H. Li, L. Hou et al., "Disorder in ball-milled graphite revealed by Raman spectroscopy," Carbon, vol. 57, pp. 515-519, 2013.
[52] JCPDS-ICDD, The International Centre for Diffraction Data, PCPDFWIN 2.4, 2003. 

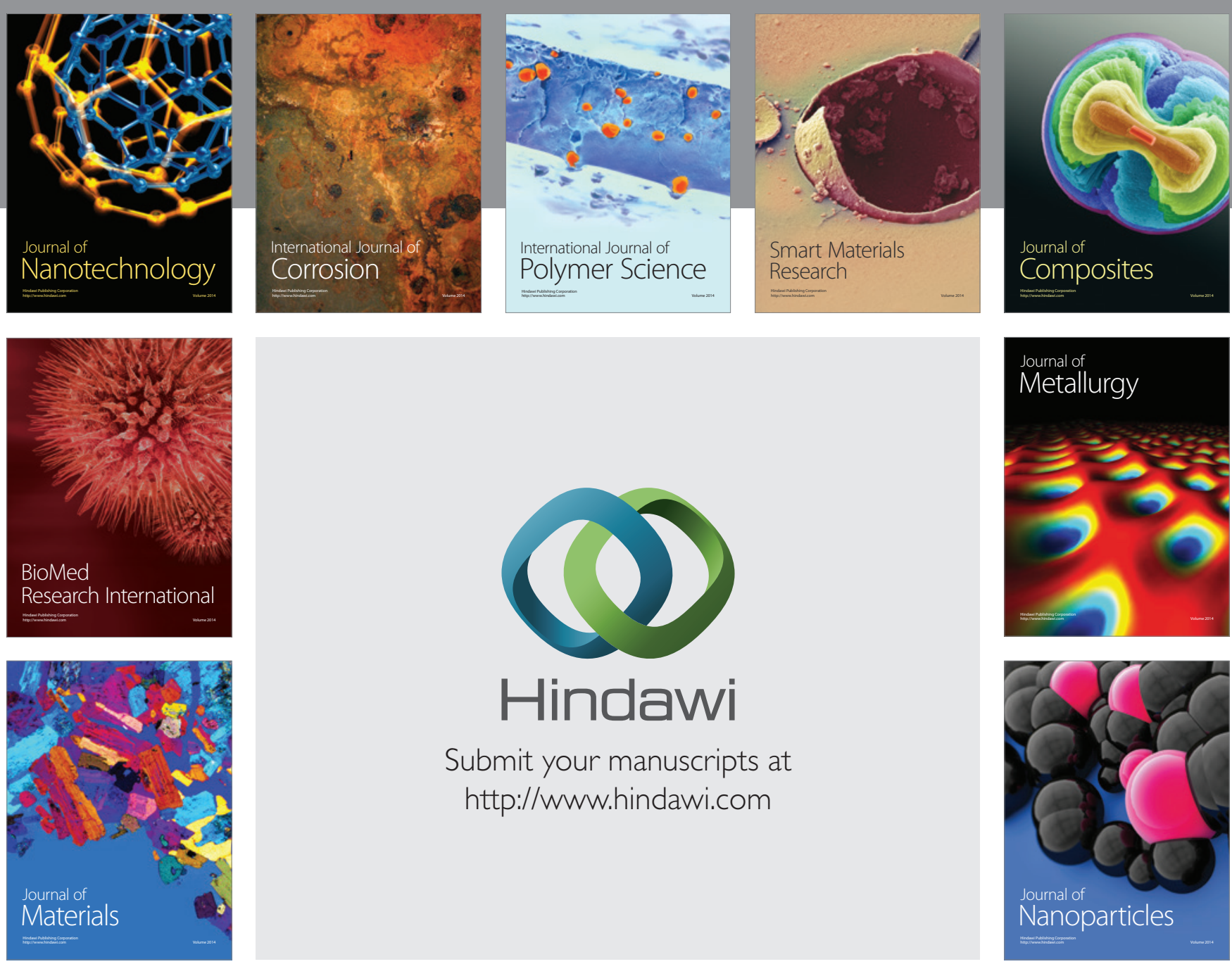

Submit your manuscripts at http://www.hindawi.com
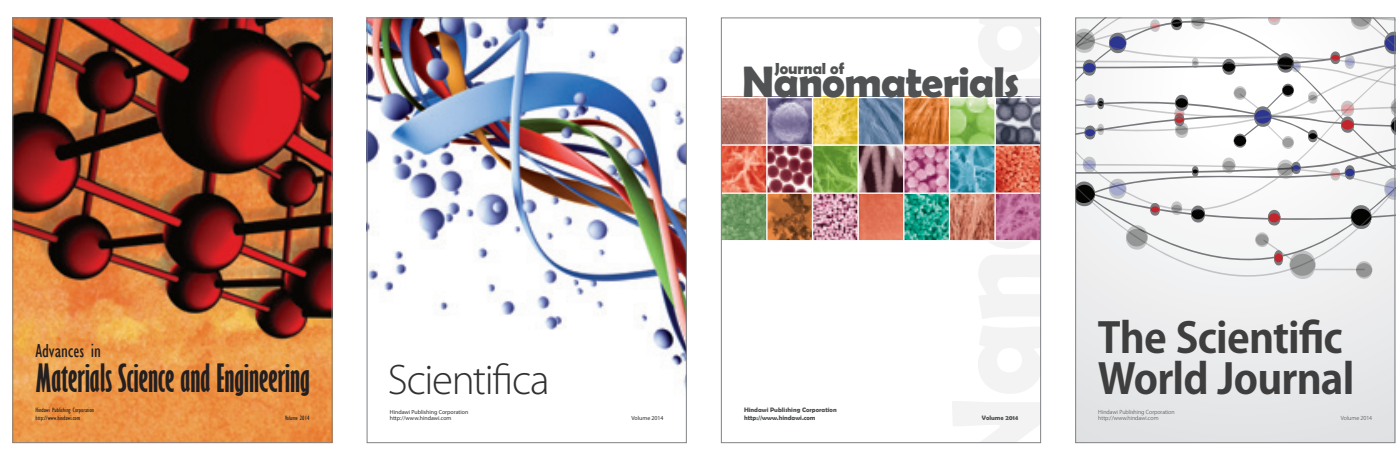

\section{The Scientific World Journal}
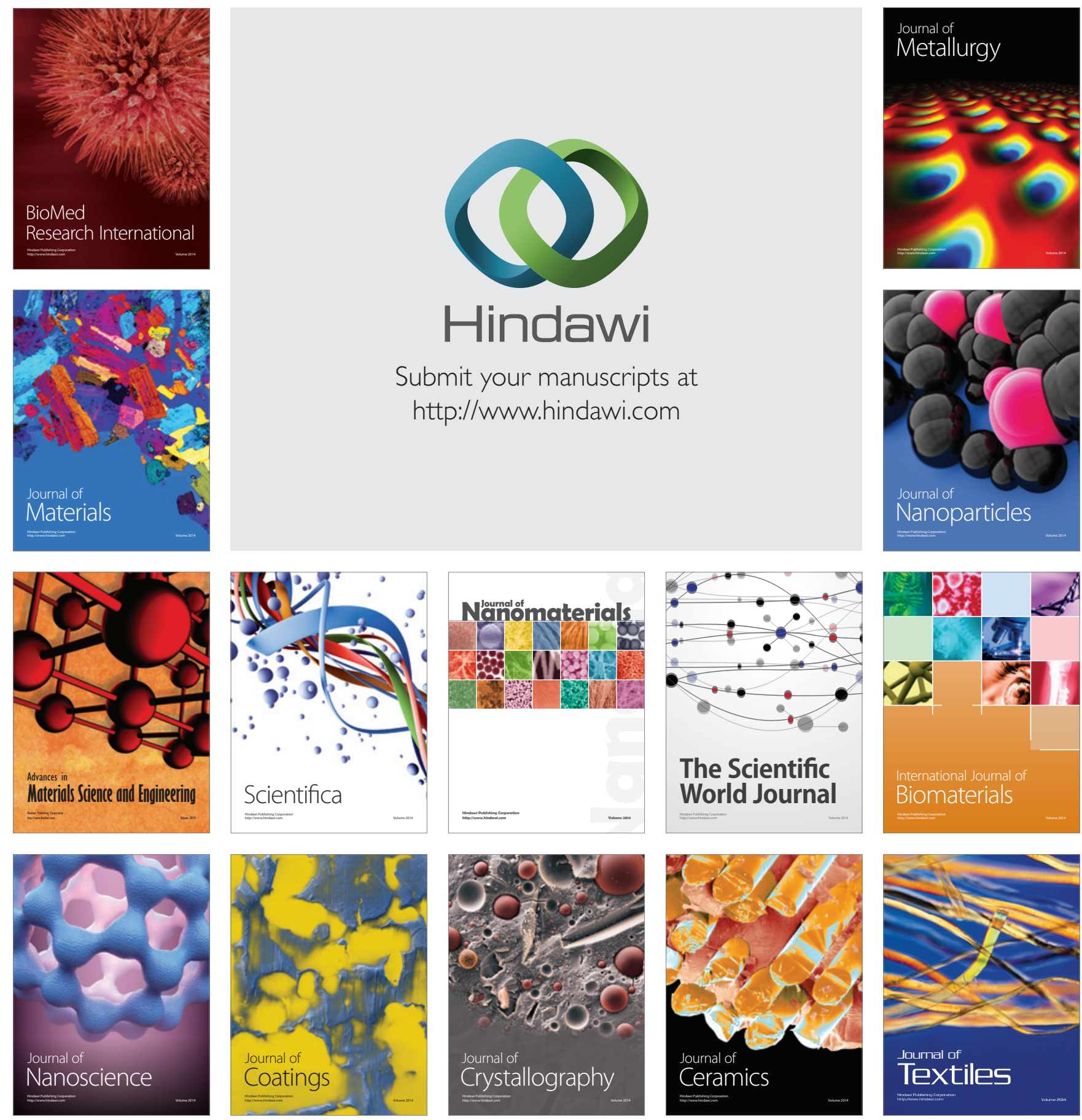